\title{
CARACTERÍSTICAS FÍSICAS E FÍSICO-QUÍMICAS DE PALITOS DE INHAME SUBMETIDOS À DESIDRATAÇÃO OSMOTICA EM SOLUÇÃO SALINA
}

\author{
T. PESSOA ${ }^{1}$; D. R. S. DA SILVA ${ }^{1}$; M. E. M. DUARTE ${ }^{2}$; M. E. M. R. CAVALCANTI MATA² ; F. F. GURJÃO ${ }^{3}$, D. S. \\ A. MIRANDA ${ }^{4}$ \\ 1, 2, 3 Universidade Federal de Campina Grande, ${ }^{4}$ Instituto Federal do Maranhão. Açailândia - MA. \\ pessoat@hotmail.com ${ }^{1}$
}

Submetido 20/07/2016 - Aceito 11/11/2017

DOI: $10.15628 /$ holos.2017.4856

\section{RESUMO}

O presente trabalho teve como objetivo determinar as características físicas e físico-químicas de palitos de inhame, In natura e após desidratação osmótica. $\mathrm{O}$ experimento foi conduzido no Laboratório de Engenharia de Alimentos pertencente à UFCG-CG. Foram utilizados inhame da variedade Da Costa, onde foram higienizados, processados e cortados em formatos de palito, em seguida submetidos à desidratação osmótica, em solução salina de $\mathrm{NaCl}$. As amostras foram avaliadas quanto aos parâmetros: Teor de água; atividade de água; $\mathrm{pH}$; acidez; amido; lipídeos; teor de sódio e as características de cor ( $L ; a ; b)$. Como conclusões têm: O teor de amido foi influenciado pelos tratamentos osmóticos, onde o uso das soluções com 5 e $10 \%$ de sal, fizeram com que os palitos de inhame apresentassem os maiores valores $(32,98)$ observados; Os teores de água dos palitos de inhame diminuem à medida que aumentam as concentrações das soluções osmóticas; $\mathrm{O}$ pH e teor de lipídeos dos palitos de inhame, não sofreram influência em nenhuma condição que foram submetidos, mantiveram-se estáveis; $O$ inhame apresenta um grande potencial para a sua agro-industrialização, seja como matéria prima para farinhas, como para novos produtos como inhame chips.

PALAVRAS-CHAVE: desidratação osmótica, caracterização, processamento, Dioscorea sp.

\section{PHYSICAL AND PHYSICOCHEMICAL YAM STICKS OF SUBMITTED TO OSMOTIC DEHYDRATION IN SALINE}

\begin{abstract}
This study aimed to determine the physical and physicochemical characteristics of yam sticks, in natura and after osmotic dehydration. The experiment was conducted at the Food Engineering Laboratory belonging to UFCG-CG. yams were used variety Coast, where they were cleaned, processed and cut into matchstick shapes then submitted to osmotic dehydration, in saline solution of $\mathrm{NaCl}$. The samples were evaluated for the parameters: water content; water activity; $\mathrm{pH}$; acidity; starch; lipids; sodium content and color characteristics ( $L, a, b)$. As
\end{abstract}

conclusions are: The starch content was influenced by osmotic treatments where the use of solutions with 5 and $10 \%$ of salt, made the yam sticks presented the highest values (32.98) observed; The water content of yam sticks decrease as increase the concentrations of osmotic solutions; The $\mathrm{pH}$ and lipid content of yam sticks, were not affected in any conditions that were submitted, remained stable; The yam has great potential for agricultural and its manufacturing or as a raw material for flour, as for new products such as yam chips.

KEYWORDS: Osmotic dehydration, characterization, processed, Dioscorea sp. 


\section{INTRODUÇÃO}

O inhame (Dioscorea sp.) é uma planta monocotiledônea, herbácea, trepadeira, de clima tropical e subtropical. As túberas possuem excelente qualidade nutritiva e energética, sendo ricas em diversas vitaminas do complexo $B$ (tiamina, riboflavina, niacina), vitamina $A$, vitamina $C$ (ácido ascórbico) e carboidrato, sendo o amido principalmente, é a principal reserva energética dos vegetais, como também é uma das principais fontes de carboidratos na dieta humana, além de apreciáveis teores de proteína e de gordura (Oliveira, Barbosa, Pereira, Silva e Oliveira, 2007).

Por ser um alimento de excelente qualidade nutritiva, energética e de preço acessível, o inhame é um item importante na alimentação dos brasileiros, podendo ser considerado como uma fonte de matéria prima para indústria de alimentos.

O desenvolvimento de produtos alimentícios, tendo como base, raízes tropicais, de tradição de cultivo e apelo cultural, como o inhame, tem atraído o interesse dos produtores rurais e industriais, pois possibilita o incremento de toda a cadeia produtiva (Crivelaro, 2008). No entanto a sua agroindustrialização, pode ser dificultada, pois a matéria-prima apresenta características que dificulta o seu processamento, como reações bioquímicas que influem na qualidade do produto final, como é o caso do escurecimento enzimático, assim sente-se a necessidade de realizar tratamentos antes de processos mais complexos.

A desidratação osmótica é um pré-tratamento utilizado para reduzir o efeito destas reações, além de melhorar a condição ao produto características agradáveis ao consumo, promovendo do amolecimento celular e da adição de solutos, além de inativar a ação de determinadas enzimas, que favorecem o escurecimento, como também se pode verificar a diminuição da atividade de água, que é forte influência no crescimento de microrganismos, conferindo uma estabilidade do alimento que será consumido.

A utilização de pré-tratamentos em produtos hortícolas, tem como finalidade prevenir ou minimizar as perdas das características referentes à sua qualidade, após essa etapa o produto poderá ser submetido a processos como a secagem convectiva e ou fritura.

Com isso, tem-se como objetivo: determinar as características físicas e físico-químicas de palitos de inhame variedade Da Costa, In natura e após desidratação osmótica, quanto aos 
parâmetros: Teor de água; atividade de água; pH; acidez; amido; lipídeos; teor de sódio e as características de cor ( $L ; a ; b)$.

\section{METODOLOGIA}

O experimento foi conduzido no Laboratório de Engenharia de Alimentos pertencente à Unidade Acadêmica de Engenharia de Alimentos da Universidade Federal de Campina Grande PB.

Foram utilizados inhames da variedade Da Costa, obtidos na EMPASA (Empresa de Abastecimento e Serviços Agrícolas da Paraíba), a matéria-prima foi selecionada a partir das características como a integridade física, tamanho e formato dos tubérculos.

Os tubérculos foram lavados em água corrente para retirada das sujidades superficiais, posteriormente foram sanificados em solução de hipoclorito a 15 ppm, durante 15 minutos com o objetivo de reduzir a microbiota, em seguida foram descascados manualmente, utilizando-se facas de aço inoxidável.

Para obtenção do inhame em formato de palitos, com dimensões de $1 \times 1 \times 4 \mathrm{~cm}$ (LxAxC), foram feitos cortes uniformes de $4 \mathrm{~cm}$ no sentido longitudinal do tubérculo, na sequência estes pedaços foram fatiados em forma de palito em máquina de fatiar batatas.

Posteriormente, os palitos de inhame foram submetidos à desidratação osmótica (DO) em soluções salinas, através do uso de $\mathrm{NaCl}$, nas concentrações de 5, 10 e $15 \%$. Utilizou-se uma proporção solução/produto de 6:1 em gramas. O processo de desidratação osmótica ocorreu em BOD condicionando as amostras na temperatura de $25^{\circ} \mathrm{C}$, onde foi mantido controle da temperatura ambiente, durante o período de 4 horas.

Para avaliar as características físicas e físico-químicas dos palitos de inhame quanto aos parâmetros: Teor de água; pH; acidez e amido utilizou-se as metodologias descritas no Adolf Lutz (2008), já para o teor de sódio utilizou-se a metodologia descrita por (Silva Junior, 2009).

A atividade de água foi realizada com o auxílio do equipamento Aqualab CX-2T, Decagon a $25^{\circ} \mathrm{C}$, apresentando erro de $\pm 0,003$ no valor final.

Os lipídeos foi determinado pelo método de destilação direta por (Bligh Dyer, 1959).

Quanto às análises de cor foram realizadas nas amostras dos palitos de inhame: in natura e após desidratação osmótica, com auxílio do colorímetro Mini scan by Hunter Lab, para os 
parâmetros $L^{*}$, que medem a luminosidade, a* intensidade de vermelho e b* intensidade de amarelo.

Para o tratamento estatístico dos dados coletados, foi realizada à análise de variância(ANOVA), com delineamento inteiramente casualizado e as médias comparadas pelo teste de Tukey, a nível de 5\% de probabilidade (Silva e Azevedo, 2010).

\section{RESULTADOS E DISCUSSÕES}

Nas Tabelas 1 e 2 encontram-se os valores médios das características físicas e físicoquímicas dos palitos inhame In natura e após os tratamentos osmóticos de 5, 10 e 15\% de sal.

Tabela 1- Características físicas e físico-químicas dos palitos inhame In natura e após os tratamentos osmóticos de 5,10 e $15 \%$ de sal

\begin{tabular}{c|c|c|c|c|c|c|c}
\hline Tratamentos & $\begin{array}{c}\text { Teor de } \\
\text { água (\%) }\end{array}$ & $\begin{array}{c}\text { Atividade } \\
\text { de água }\end{array}$ & $\mathbf{p H}$ & $\begin{array}{c}\text { Acidez } \\
\text { (\% de acido } \\
\text { citrico) }\end{array}$ & $\begin{array}{c}\text { Amido } \\
\text { (\%) }\end{array}$ & $\begin{array}{c}\text { Lipídeos } \\
\text { (\%) }\end{array}$ & $\begin{array}{c}\text { Teor de } \\
\text { sódio (\%) }\end{array}$ \\
\hline In natura & $76,25 \mathrm{a}$ & $0,997 \mathrm{a}$ & $6,22 \mathrm{a}$ & $0,520 \mathrm{a}$ & $27,23 \mathrm{c}$ & $0,594 \mathrm{a}$ & $0,106 \mathrm{~d}$ \\
$\mathbf{5 \%}$ DO & $68,61 \mathrm{~b}$ & $0,985 \mathrm{~b}$ & $6,33 \mathrm{a}$ & $0,521 \mathrm{a}$ & $32,98 \mathrm{a}$ & $0,594 \mathrm{a}$ & $0,517 \mathrm{c}$ \\
$\mathbf{1 0 \%}$ DO & $66,67 \mathrm{~b}$ & $0,979 \mathrm{c}$ & $6,24 \mathrm{a}$ & $0,437 \mathrm{~b}$ & $32,98 \mathrm{a}$ & $0,589 \mathrm{a}$ & $0,540 \mathrm{~b}$ \\
15\% DO & $65,45 \mathrm{~b}$ & $0,977 \mathrm{c}$ & $6,32 \mathrm{a}$ & $0,437 \mathrm{~b}$ & $31,16 \mathrm{~b}$ & $0,595 \mathrm{a}$ & $0,559 \mathrm{a}$ \\
\hline DMS & 3,2777 & 0,0044 & 0,1145 & 0.06620 & 1,3761 & 0,0138 & 0,0115 \\
\hline C.V. & 1,81 & 0,17 & 0,70 & 5,29 & 1,69 & 0,90 & 1,03 \\
\hline
\end{tabular}

Médias seguidas das mesmas letras nas linhas não diferem entre si pelo teste de Tukey a $5 \%$ de probabilidade DMS = Diferença minima Significativa

$\mathrm{CV}=$ Coeficiente de variação

DO= Desidratação Osmótica

Para o teor de água das amostras, verifica-se que estes diminuem à medida que se aumenta a concentração de sal na solução osmótica, onde a amostra com maior média foi a in natura com 76,26 \% de água, já os palitos de inhame com menor valor foram obtidos após a desidratação em solução salina de $15 \%$, percebe-se que as amostras tratadas osmoticamente desmontraram ser estatisticamente iguais. Para a atividade de água, foi observado o mesmo comportamento, em que o maior valor médio foi obtido para a amostra in natura com 0,997 e o menor valor para amostra imersa em solução com $15 \%$ de sal apresentando média de 0,977 , no entanto verifica-se que ocorreu um decréscimo nesses valores, mas as amostras tratadas a 10 e $15 \%$ de sal, apresentaram-se estatisticamente iguais. O comportamento apresentando ocorreu devido o fator desidratação, pois à medida que se retira água do alimento esses índices tendem a diminuir, dificultando a proliferação de microrganismos.

Aquino, Santos, Castro e Silva (2011) ao avaliarem as características de inhame para produção de farinha obtiveram médias de teor de água 64,8 $\pm 0,2$ e atividade de água 0,920 $\pm 0,030$. Nunes (2009) ao estudar inhame para produção de fécula, obteve para sua matéria prima 
o teor de água 73,90 \% $\pm 1,46$, Rogério e Leonel (2004) em estudo de chips de inhame, encontraram teor de água de 89,69 \pm 0,74 para o produto antes da fritura. Leonel e Cereda (2002) encontraram valores 75,30 $\pm 0,97$ ao analisar tuberosas amiláceas. Paula, Pirozi, Puiatti, Borges e Durango (2012) ao avaliarem variedades de inhame cará, observaram valores que variaram entre 68,9 a $72,1 \%$ no teor de água, pode-se perceber que os valores encontrados no estudo atual de inhame, estão próximos aos da literatura citada.

Quanto ao $\mathrm{pH}$ dos palitos de inhame, pode-se perceber que não ocorreu diferença significativa entre os tratamentos utilizados, em que seus valores variaram entre 6,22 a 6,33. Nunes (2009) em seu estudo encontrou menores valores de pH 5,52 $\pm 0,01$, Leonel e Cereda (2002) encontraram valores próximos ao da pesquisa 6,13 $\pm 0,07$ mesmo teor encontrado por Leonel, Sarmento e Ferrari (2005).

Para a acidez pode-se observar que os palitos de inhame que foram imersos em solução salina de maior concentração (10 e 15\%) apresentaram menores valores 0,437 (\% de acido citrico), já as amostras in natura e imersas na solução de 5\% de sal, apresentaram média de acidez 0,521. Nunes (2009) encontrou valores mais altos de acidez 1,07 $\pm 0,18$, já Leonel e Cereda (2002) obtiveram valores de $6,66 \pm 0,08$, demonstrando ser maior que os observados na pesquisa. Brito, Soares, Furtado, Castro e Carnelossi (2011) ao analisarem inhames processados minimamente encontraram valores médios de acidez 0,06 (\% de ácido cítrico). Tais diferenças entre os pesquisadores, pode ter relação direta entre a maturação que a matéria prima foi utilizada nas pesquisa, como também algumas características relacionadas aos tratos culturais no momento de produção.

Com relação a quantidade de amido contido nas amostras, pôde-se perceber que o conteúdo da amostra in natura $(27,23 \%)$ foi menor quando comparado com as amostras após DO, estas amostras apresentaram valores superiores a $30 \%$, verificando-se que os maiores valores foram obtidos para as amostras após desidratação de 5 e $10 \%$ de sal, esse incremento no percentual de amido, pode ser justificado pelo fato da osmose permitir que o alimento obtenha um menor percentual de água, assim ocorre uma concentração do parâmetro analisado. Nunes (2009) em seu estudo encontrou teor de amido de 17,30 $\pm 0,14$ na amostra in natura, já Leonel e Cereda (2002) um teor de amido de 20,43 $\pm 0,13$. Oliveira, Freitas Neto e Santos (2002) avaliaram vários tipos de adubação na qualidade dos rizomas, encontraram valores próximos de 31,6\%, o que justifica a variação do teor de amido, com as características relacionadas a variedade 
cultivada, épocas de colheita, maturação e os tratos culturais utilizados. Paula et al. (2012) ao analisarem a quantidade de carboidratos, verificam variação entre 87,3 a 91,3, caracterizando como um alimento de alto valor energético devido ao teor de carboidratos totais, predominantemente presente na forma de amido. Os teores de amido encontrados por Brito et al. (2011) são próximos aos observados no estudo atual, com teor médio 29,5\%.

As amostras analisadas apresentaram valores de lipídeos (\%) variando entre 0,594 a 0,595, podendo verificar que não houve diferença estatística entre os tratamentos utilizados. Nunes (2009) encontraram valores médios 2,65 $\pm 0,13$, maior que os apresentados no estudo. Já Rogério e Leonel (2004) analisaram a matéria prima inhame observaram valores médios de 0,04 $\pm 0,01$. Paula et al. (2012) encontraram valores entre 0,25 a 0,45 \% em sua pesquisa para diferentes variedades de inhame. Já Brito et al. (2011) observaram valores de 0,86 \% de lipídeos em inhame minimamente processados.

A quantidade de sódio presente nas amostras variou de acordo com a solução em que os palitos de inhame foram imersos. Para os palitos de inhame in natura observa-se valores médios 0,106 \%, depois da desidratação osmótica apresentaram valores médios de 0,517; 0,540 e 0,559 para as amostras imersas em 5, 10 e $15 \%$ de sal, respectivamente.

Para a análise de cor pode-se verificar as seguintes características de luminosidade $\left(L^{*}\right)$, intensidade de vermelho $\left(+a^{*}\right)$ e intensidade de amarelo $\left(+b^{*}\right)$ dos palitos de inhame In natura e após desidratação osmótica (Tabela 2), observa-se que os valores de luminosidade diminuíram a medida que foram imersos nas soluções salinas, onde a amostra In natura apresentou um valor de 85,263, após a DO os valores 83,276; 74,593 e 73,666 para as concentrações osmóticas de 5, 10 e $15 \%$ respectivamente. Tal fato pode ocorrer devido ao escurecimento enzimático. Brito et al. (2011) ao estudar amostras processadas minimamente verificou valores L* entre 67,7 e 67,1, para o tratamento controle e o processado, respectivamente, essa diferença apresentada na pesquisa, pode ocorrer devido as formas de pré tratamanto em que as amostras são condicionadas e o ambiente de armazenamento 
Tabela 2- Análise de cor do inhame In natura e após tratamentos osmóticos

\begin{tabular}{c|c|c|c}
\hline & $\mathbf{L}$ & $\mathbf{a}$ & $\mathbf{b}$ \\
\hline In natura & $85,263 \mathrm{a}$ & $-1,186 \mathrm{a}$ & $25,150 \mathrm{a}$ \\
$\mathbf{5 \%}$ de DO & $83,276 \mathrm{~b}$ & $-0,866 \mathrm{~b}$ & $26,450 \mathrm{a}$ \\
$\mathbf{1 0 \%}$ de DO & $74,593 \mathrm{c}$ & $-0,760 \mathrm{bc}$ & $16,550 \mathrm{a}$ \\
$\mathbf{1 5 \%}$ de DO & $73,666 \mathrm{c}$ & $-0,660 \mathrm{c}$ & $29,296 \mathrm{a}$ \\
\hline DMS & 1,3031 & 0,1167 & 15,8883 \\
\hline C.V. & 0,63 & 5,14 & 24,94 \\
\hline
\end{tabular}

Médias seguidas das mesmas letras nas linhas não diferem entre si pelo teste de Tukey a $5 \%$ de probabilidade DMS = Diferença minima Significativa

$\mathrm{CV}=$ Coeficiente de variação

DO= Desidratação Osmótica

Quanto à intensidade de vermelho (a*) pôde-se observar que amostras obtiveram valores menores que zero, que segundo Minolta (1994) tendem apresentar variação de cor para proximidade do verde, tal observação pode ser influenciada pela maturação que a matéria prima foi colhida. Os valores de "a*" diminuíram com o processo de desidratação, em que a In natura apresentou o valor de -1,186 e para os tratamentos após osmose -0,866; -0,760 e -0,660 para 5, 10 e 15 \% de solução salina, respectivamente.

Para a intensidade de amarelo ( $b^{*}$ ) identificam-se valores próximos em todos os tratamentos utilizados, que demonstram serem iguais estatisticamente. Os valores observados são maiores que zero, pode-se considerar que ocorreu uma maior presença da cor amarela. A amostra que apresentou maior valor $(29,296)$ de "b*" foi amostra após DO em solução salina de 15 \%, já o menor valor $(16,55)$ foi observado na amostra imersa em solução contendo $10 \%$ de sal. O fato de apresentar uma coloração mais amarelada pode estar relacionado a variedade de inhame que foi utilizada no experimento. Brito et al. (2011) em seu estudo encontrou valores próximos, onde o tratamento controle teve média de 30,3 e para o inhame processado minimamente de 26,8 .

\section{CONCLUSÕES}

O inhame apresenta um grande potencial para a sua agroindustrialização, seja como matéria prima para farinhas, como para novos produtos como inhame chips.

Os teores de água e a atividade de água dos palitos de inhame diminuem à medida que aumentam as concentrações das soluções osmóticas;

$\mathrm{O}$ pH e teor de lipídeos dos palitos de inhame, não sofreram influência em nenhuma condição que foram submetidos, mantiveram-se estáveis; 
A acidez foi influenciada pelo teor de sal das soluções osmóticas, onde as amostras tratadas com 10 e $15 \%$ de sal obtiveram os menores valores (0,540\%; 0,559\%), respectivamente;

O teor de amido foi influenciado pelos tratamentos osmóticos, onde o uso das soluções com 5 e $10 \%$ de sal, fizeram com que os palitos de inhame apresentassem os maiores valores $(32,98)$ observados;

Os teores de sódio das amostras avaliadas sofreram influência dos tratamentos osmóticos, com o acréscimo do percentual de sal, ocorreu o aumento no teor avaliado;

As luminosidades (L) e a intensidade de vermelho (a) dos palitos de inhame diminuíram com o aumento da concentração das soluções osmóticas.

\section{REFERÊNCIAS}

Aquino, A. C. M. S.; Santos, J. C.; Castro, A. A. \& Silva, G. F.(2011). Caracterização físico-química e microbiológica de farinha de inhame durante o armazenamento em diferentes embalagens. Scientia Plena. 11(7), 1-5 .

Brito, T. T.; Soares, L. S.; Furtado, M. C.; Castro, A. A. \& Carnelossi, M. A. G. (2011). Composição centesimal de inhame (Dioscorea sp.) In natura e minimamente processado. Scientia Plena, 7(6), 1-7.

Crivelaro, M. Quem melhor combate a fome? AGROSOFT BRASIL, 2008. Disponivel em: <www.agrosoft.org.br/agropag/100080.htm>. Acesso em: 4 de jul. 2016.

Instituto Adolfo Lutz. (2008). Métodos físico-químicos para análise de alimentos(4a ed., pp. 1020). São Paulo:Instituto Adolfo Lutz.

Leonel, M. \& Cereda, M. P. (2002). Caracterização físico-química de algumas tuberosas amiláceas. Ciência e Tecnologia de Alimentos, 22(1), 65-69.

Leonel, M.; Sarmento, S. B. S. \& Ferrari, T. B. (2005). Aproveitamento do gengibre (Zingiber officinale) de qualidade inferior como matéria-prima amilácea. Revista Raízes e Amidos Tropicais, 1, 9-18.

Minolta. (1994). Precise color communication: color control from feeling to instrumentation. MINOLTA Co. Ltda.

Nunes, L. S. (2009). Obtenção de amido de inhame e sua utilização no preparo de alimentos à base de leite (Dissertação de mestrado em Engenharia Agrícola), Universidade Federal de Campina Grande, Campina Grande, PB, Brasil. 
Oliveira, A. P.; Barbosa, L. J. N; Pereira, W. E.; Silva, J. E. L. \& Oliveira, A. N. P. (2007). Produção de túberas comerciais de inhame em função de doses de nitrogênio. Horticultura Brasileira, Brasília, 25, 073-076.

Oliveira, A.P.; Freitas Neto, P.A. \& Santos, E.S. (2002). Qualidade do inhame 'Da Costa' em função das épocas de colheita e da adubação orgânica. Horticultura Brasileira, 20(1), 115-118.

Paula, C. D.; Pirozi, M.; Puiatti, M.; Borges, J. T. \& Durango, A. M. (2012). Características fisicoquímicas y morfológicas de rizóforos de ñame (Dioscorea alata). Biotecnología en el Sector Agropecuario y Agroindustrial, 10(2), 61-70.

Rogério, W. F. \& Leonel, M. (2004). Efeitos da espessura das fatias e pré-cozimento na qualidade de salgadinhos fritos (chips) de tuberosas tropicais. Alimentos e Nutrição, Araraquara, 15(2), 131-137. 